\title{
El delito económico y los modos neoliberales de gobierno: el ejemplo de la región mediterránea'
} Economic Crime and Neoliberal Modes of Government: The Example of the Mediterranean

\author{
Beatrice Hibou \\ Centre d'Études et de Recherches Internationales (CERI) \\ beatrice.hibou@sciencespo.fr
}

7

odo el mundo oyó hablar, en diciembre de 2008, del problema de las basuras en Nápoles y en Campania cuando Silvio Berlusconi desplegó el ejército para recogerlas y declaró la región en estado de emergencia. Es sabido que, en Italia, la Camorra reúne desechos tóxicos al aire libre y que administra botaderos y basureros sin siquiera tener vertederos para tratar las basuras domiciliarias de la región. Pero ¿podemos quedarnos con esta versión de la historia, que muestra a una mafia malvada frente a un estado impotente? Evidentemente no, porque la crisis de 2008 es solamente uno de los episodios de un círculo vicioso mucho más complejo que comenzó por lo menos en 1994, con la primera declaración de estado de emergencia en la región y la instalación de un alto comisionado dedicado a ese problema (Gribaudi 2008). En el origen del desastre está, por una parte, una empresa encargada del tratamiento de basuras y, por otra, la administración pública provista de políticas para supervisarla.

1 Traducción del artículo "Economic Crime and Neoliberal Modes of Government: The Example of the Mediterranean", publicado en 2012 en el Journal of Social History 45 (3): 642-660. El ICANH obtuvo de la editorial Oxford University Press y de Beatrice Hibou los derechos de traducción y reimpresión del manuscrito en inglés. 
La empresa en cuestión, que no está ligada a la Camorra sino a la muy "limpia” y legítima FIAT (Fabbrica Italiana Automobili Torino) trató de sacar provecho fácil y rápido del estado de emergencia a cambio de prestar unos servicios de malacalidad y cometió verdaderas negligencias industriales: propuso un proyecto técnico muy débil y engañó al estado en cuanto a la calidad de sus servicios, escogió equipos obsoletos que requerían vertederos, estuvo siempre retrasada en la instalación de las plantas de tratamiento, recurrió a una subcontratación poco escrupulosa y transfirió el costo de su ineficiencia al alto comisionado. Los dirigentes y los administradores locales, por su parte, administraron los movimientos de dineros a través de las oficinas del mencionado alto comisionado, y con ello reforzaron su poder y extendieron sus redes de amigos y clientes. Al amparo del estado de emergencia, aceptaron además derogaciones como la subcontratación y eligieron, durante el curso mismo de una licitación, a la empresa que prometía actuar en un lapso de tiempo más corto, aunque ofreciera prestaciones mínimas. Utilizaron también sus poderes extraordinarios para escapar de los circuitos y mecanismos tradicionales de vigilancia en la administración pública; no controlaron los pliegos de condiciones del contrato y fueron incapaces de imponer un tratamiento diferenciado de los desechos; administraron el negocio contratando mano de obra de manera clientelista y usaron los fondos para multiplicar los estudios y aumentar la remuneración de los dirigentes. La Camorra no tuvo nada que ver con esta situación: ni creó ni inspiró la operación. Por medio de subcontratos y licitaciones para el transporte de desechos y manejo de vertederos, se limitó a responder a una demanda, a explotar una oportunidad suplementaria de negocios y aprovechó la incapacidad histórica de control de las instituciones públicas.

Este caso es un excelente ejemplo de la tesis que quiero desarrollar. Una representación ilusoria de la realidad —en este caso, una Camorra omnipotente que constituye la fuente de todo mal- muestra cómo la condena al crimen organizado permite nuevas intervenciones estatales, tales como el uso de poderes derivados del estado de emergencia y el desarrollo de asociaciones público-privadas, y oculta mecanismos y prácticas — como la subcontratación y las licitaciones mal manejadas - que son mucho más problemáticos, aunque difícilmente condenables precisamente porque hacen parte del orden neoliberal. Lo que me propongo más precisamente con este artículo es mostrar que la denuncia de los delitos económicos se inscribe en el orden neoliberal por cuanto ayuda al estado a reestructurar sus intervenciones y permite la coexistencia de configuraciones del neoliberalismo, simultáneas pero no necesariamente compatibles, si entendemos este último no solamente como un orden económico — una fase del capitalismo- sino también como un orden político. 
Desde los años ochenta, se ha descrito el neoliberalismo como el fin del proteccionismo estatal en los países europeos, el establecimiento de programas de ajustes estructurales en los países en desarrollo y la transición hacia una economía de mercado en los antiguos países socialistas. También se ha hablado de un desafío a la soberanía económica de los estados, que parecen reducidos a la impotencia en la escena económica globalizada. Pero, más allá de las apariencias y los estereotipos acerca de la supremacía de los mercados, el auge de los actores trasnacionales, la supuesta ineficiencia de los estados para regular el capitalismo y el dominio de las consideraciones económicas y financieras, se puede ver el desarrollo de otras formas y calidades del estado, y de sus capacidades regulatorias, así como cambios en la relación entre lo económico y lo político, lo público y lo privado, lo lícito y lo ilícito.

En este nuevo orden, hay un relanzamiento del estado, el cual, muy lejos de volverse impotente, toma otra orientación, con base en la crítica del intervencionismo directo, y actúa por delegación o como gobierno a distancia, es decir, que recurre a asociaciones con los entes privados y actúa a través de una burocratización renovada bajo los rasgos de una nueva administración pública basada en normas, de una disciplina impuesta a través de reglas, de la evaluación individual cuantificada e individualizante y del autocontrol. Sin embargo, este relanzamiento toma la forma de un intervencionismo totalmente directo en todo lo que puede calificarse como seguridad. Desarrolla mecanismos de vigilancia de los espacios tanto públicos como privados, instaura una disciplina por medio del seguimiento continuo de los desplazamientos y la evaluación detallada de las actividades de los individuos, y logra el autocontrol de los sujetos a través de las normas y reglas del momento. El paso por la criminalización y la reificación de figuras que representan "el mal" (el terrorista, el contrabandista, el mafioso, el crimen organizado) se convierte en una oportunidad para preparar el terreno de posibles intervenciones estatales - la condición para nuevas acciones del estado-. Se trata entonces de una oportunidad para fortalecer la dominación política por medio de intermediarios y actores privados.

\section{El delito económico visto como peligro primordial}

A partir de los años noventa, la criminalidad económica se ha convertido en el objeto de un discurso alarmista global según el cual las actividades delictivas pondrían en riesgo la democracia y la participación de los ciudadanos en ellas constituiría el peligro más importante para la globalización contemporánea 
(Baker 2008; Glenny 2008; Naím 2005). Tal como sucede en las grandes empresas, el crimen reforzaría su poder con su capacidad de sellar alianzas internacionales, lo que permitiría la existencia de espacios no regulados cada vez más amplios y tolerados en parte por los estados y el sistema internacional (Allen 2006; Castells 1998; Conway 2006; Conway y Heynen 2006), y contribuiría a transformar el estado en un actor ordinario (Hall y Biersteker 2000; Strange 2006) que ha perdido su monopolio de la ilegalidad legítima. En Europa, este discurso subraya la participación del crimen organizado en todo tipo de tráficos y lavado de dinero y, para construir este argumento, se lleva a cabo una mezcla inquietante de migraciones, terrorismo y criminalidad económica. Gradualmente, la retórica del peligro que amenaza a Europa ha evolucionado hacia una especie de mentalidad de asedio obsesionada con una Unión Europea, virtuosa por definición, que se ve legítimamente obligada a constituirse en fortaleza (Hibou 2003c). El peligro que la sitiará se ve venir tanto del este, de los antiguos países socialistas desestructurados desde la caída del muro de Berlín y dominados por grupos mafiosos, como del sur, en una reformulación desequilibrada del mito europeo del Mediterráneo que destaca cualquier cosa diferente, lo otro —el musulmán, por ejemplo-y lo rechazado - la droga, los migrantes clandestinos, el terrorismo-. Esto es lo que los intelectuales europeos han llamado la obsesión pirata (Abel 2009; Garapon 2009; Mongin 2009), según la cual la droga, el crimen organizado, el dinero sucio, el terrorismo, los delitos medioambientales y el tráfico de personas vienen a "piratear” el orden sereno de una Europa puritana.

Este discurso suscita malestar. Para tratar de construir la imagen del delito económico como "la plaga del siglo XXI", se han mezclado conceptos, se han inventado relaciones o se las ha exagerado, se han extrapolado cifras, se han planteado relaciones de causa-efecto sin acreditar necesariamente las pruebas correspondientes, y sin exponer hipótesis o dudas. Se reifica a las mafias y a otros delincuentes, aun a los delincuentes económicos, y se plantea una estricta separación entre actores legales, lícitos y legítimos opuestos a los ilegales, ilícitos e ilegítimos. Sin embargo, las escasas cifras de lavado de dinero, falsificaciones, tráfico de droga y contrabando - que por naturaleza son estimaciones - reposan a su turno sobre construcciones frágiles y altamente dependientes de los cuerpos represivos, cuya razón de ser consiste justamente en llamar la atención sobre estos fenómenos (Briquet y Favarel-Garrigues 2008; Dillman 2007; Heyman 1999; Schendel y Abraham 2005). Tal como nos lo recuerda Eiko Siniawer (2012) en su artículo, no podemos simplificar las relaciones entre el estado y las organizaciones criminales, pues no son entidades monolíticas. Además, no hay que olvidar que también entran en juego otros actores, como empresarios, banqueros, políticos, asesores contables y jurídicos, etc. Por último, la naturaleza de sus relaciones 
es extremadamente compleja y ambigua: va de la protección a la oposición, de la alianza al conflicto, de la tolerancia a la intolerancia y de la delegación a la contención, en situaciones muy fluidas e inestables. Es necesario averiguar cómo se construye este discurso acerca de la criminalidad globalizada y las razones por las cuales los actores estatales, así como un gran número de observadores que se proclaman independientes e incluso académicos universitarios, caen en la trampa de construir la imagen de un peligro externo que amenaza tanto a los estados como a la sociedad.

Tres tipos de trabajos tuvieron influencia en la definición de esta tesis y su sustentación. La primera fuente es el conjunto de investigaciones que han mostrado que las actividades criminales forman parte integral de la economía oficial y del neoliberalismo contemporáneo ${ }^{2}$. Un segundo corpus proviene de los trabajos que sugieren la existencia de una paradoja aparente en el neoliberalismo: una moralización sin precedentes en la vida económica y política, una reificación de la ley y del estado de derecho y, simultáneamente, la denuncia de la persistencia de las ilegalidades en el seno mismo de los estados y de una criminalidad económica creciente que se convierte en un peligro para el conjunto de la sociedad (Bayart 2008; Briquet y Favarel-Garrigues 2008; Dardot y Laval 2009; Heyman 1999). La tercera fuente de inspiración procede de los escritos de sociología histórica, considerados ya como clásicos, que en el tema europeo comenzaron con Charles Tilly $(1975,1985)$ y se han renovado en relación con las situaciones actuales en varios sitios del mundo. Estos tres elementos muestran que la ley y el crimen hacen parte de la misma historia en cuanto a la formación del estado y que la criminalidad no es lo contrario de la legitimidad estatal. Las transformaciones actuales no deben ser analizadas en términos de retiro o de debilitamiento del estado, sino en términos de un relanzamiento de este a través de nuevas modalidades de regulación y de nuevas relaciones entre lo público y lo privado, lo lícito y lo ilícito³.

A través de las nociones de riesgo, peligro generalizado y seguridad, la problemática de la criminalidad económica juega un papel fundamental en este relanzamiento estatal de dos maneras, por lo menos. Por una parte, se lleva a cabo por medio de la construcción de lo que es criminal, ilegal o ilícito y de lo que no lo es (Briquet y Favarel-Garrigues 2008; Hillyard et al. 2004; Schendel y Abraham 2005). Por otra, la definición de lo criminal, lo ilegal y lo ilícito procede de tensiones, luchas, conflictos y compromisos. Dicho de otra manera,

2 Véanse Péraldi (2001); Hibou (1998b, 2003a); Naylor (2002); Lowenhaupt (2006); Adelkhah y Bayart (2007); Favarel-Garrigues, Godefroy y Lascaumes (2009) y Gribaudi (2009). 
depende del ejercicio del poder y la dominación ${ }^{4}$. La estigmatización de algunos actores y comportamientos forma parte del significado político del neoliberalismo y la marca crimen organizado juega un papel fundamental en este ejercicio ${ }^{5}$.

Mi ensayo sugiere, tal como lo hace Eiko Siniawer (2012) en un contexto diferente, que la naturaleza de las relaciones entre estado y delito, o más bien, la manera como el estado percibe la criminalidad económica, nos permite comprender mejor los actuales modos de gobierno. Planteo que tal construcción de la idea de criminalidad económica esconde una realidad básica de la transformación actual de los estados europeos. Lejos de estar debilitados por amenazas externas del crimen organizado, los estados están relanzando su poder por medio de nuevos modos de regulación y de nuevas relaciones entre lo público y lo privado, y lo lícito y lo ilícito (Hibou 1998a, 1999). La construcción de la idea de criminalidad económica y la estigmatización de los presuntos delincuentes surgen de los conflictos de poder subyacentes, de las negociaciones implícitas y de los compromisos de un neoliberalismo en desarrollo que constituye un orden tanto político como económico. Un análisis de las migraciones ilegales, del lavado de dinero y del contrabando muestra que la lucha contra el crimen organizado termina por legitimar la intervención estatal renovada en una amplia escala política. Promoviendo los principios neoliberales de desregulación y flexibilidad económica, la competencia, la rentabilidad y la competitividad a cualquier precio, e incluso criminalizando a algunos actores económicos que operan en este ámbito, los estados están imponiendo un poder político cada vez más fuerte sobre sus poblaciones.

\section{La criminalización de las migraciones irregulares en la región mediterránea - la rehabilitación de una concepción anticuada de la soberanía en nombre de una nueva visión del estado}

Ya es corriente presentar el carácter ilegal de las migraciones en el Mediterráneo como el resultado de políticas europeas contradictorias que hacen cohabitar,

\footnotetext{
4 Esto proviene directamente de la influyente obra ya clásica de sociólogos e historiadores tales como Marx, Weber, Tilly o Foucault.

$5 \quad$ Véanse Bayart, Ellis y Hibou (1998); Coleman (2004); Coleman, Tombs y Whyte (2005); Bayart (2008); Vallée (2010); Favarel-Garrigues (2007); Briquet y Favarel-Garrigues (2008); Gribaudi (2009); Faravel-Garrigues, Godefroy y Lascoumes (2009).
} 
por una parte, liberalización, globalización y desaparición de las fronteras para los movimientos de bienes, ideas y capitales y, por el otro, el control y el cierre de las fronteras para los movimientos de personas. El cierre de las fronteras es reciente, se decidió en Europa entre mediados de los años setenta y finales de los ochenta, en el momento en que la apertura de las fronteras económicas se convertía en credo mundial. La explicación más corriente indica que pudo haber sido una respuesta a un sentimiento de inseguridad producido por el neoliberalismo, que se caracteriza por el flujo y la libertad de movimientos en un espacio globalizado: una inseguridad de la población, que comienza a pedir protección, pero también una inseguridad de los estados frente a la pérdida de su influencia sobre el flujo y las actividades económicas. Según este punto de vista, las directivas y la legislación europeas expresan la voluntad pública y el ejercicio de un control efectivo por parte de los actores estatales. Sin embargo, esta resulta ser una explicación superficial y su persistencia intriga, teniendo en cuenta que los migrantes siguen llegando sin que se les persiga ni se les expulse sistemáticamente. Este es otro elemento conocido de la ecuación: los empleadores que utilizan esta mano de obra no son judicializados, ni siquiera se los incomoda, y de esta manera se promueve cierta forma de inmigración cuya ilegalidad misma alimenta la agenda neoliberal.

Tanto la ribera norte como la ribera sur del Mediterráneo se han caracterizado históricamente por tener importantes economías informales. Sin embargo, el enorme alcance de la migración ilegal no puede entenderse sin analizar la evolución complementaria que ha tenido el sector productivo europeo, concretamente el impulso al aumento de los beneficios debido a la contratación de mano de obra por outsourcing ${ }^{6}$. Esta tercerización toma tres formas principales: la primera es la de la cadena de subcontratación, que oculta varios niveles de empresas detrás del subcontratista oficial y que es la más conocida; la segunda consiste en el uso de agencias de trabajo temporal que permite a las empresas subcontratistas enfrentar la inestabilidad del mercado con la gestión de una mano de obra totalmente flexible de la manera más rápida y más burda. Estas compañías habitualmente se roban las primas de trabajo, deducen gastos de la hoja de pago, hacen fraude en las contribuciones al sistema de salud y a la seguridad social y, sobre todo, dejan sin firmar los contratos laborales a término fijo. Este último procedimiento es fundamental porque permite despedir al trabajador en cualquier momento y legalizar su situación a posteriori, haciendo que firme su contrato por el término que laboró realmente. El trabajo temporal

$6 \quad$ Para todas estas transformaciones, entre muchas otras, véanse Garson y Mouhoud (1989); Pupier (1992); Coutrot (1998); Boltanski y Chiapello (1999), y Durad (2004). 
no solo se presta entonces para el proceso de tercerización de la mano de obra, sino también para la tercerización de las ilegalidades ${ }^{7}$. La tercera forma es el trabajo a destajo encargado por sociedades transnacionales (Baganha 2001; Hibou 2003a; Math y Spire 2006). Desde los años noventa, falsas compañías trasnacionales de países con bajos salarios y bajos niveles de protección social (Portugal inicialmente y ahora los países de Europa del Este) envían a sus trabajadores a otros países europeos. Dado que estas compañías tienen únicamente empleados de exportación, son empresas fachada que aparentan tener un carácter trasnacional con el fin de esconder la ilegalidad de sus contratos (Jounin 2008).

Aunque los inmigrantes sin identificación o los que tienen identificaciones falsas son obviamente los trabajadores más vulnerables, y están sujetos a ser deportados en cualquier momento, los inmigrantes legales también se ven afectados, porque las fronteras entre lo legal y lo ilegal a menudo se vuelven difusas. En Francia, por ejemplo, un permiso de un año no tiene asegurada su renovación y, en Italia, el estatus de los inmigrantes desempleados se tolera únicamente durante dos años, después de los cuales muchos de ellos se convierten en ilegales (Math y Spire 2004; Quassoli 1999). En casi todos los países europeos, la legalización discrecional puede crear inmigrantes ilegales permanentes con solo redefinir el estatus de los inmigrantes legales (Jounin 2008; Math y Spire 2004; Samson 2006).

Existen por lo menos cuatro canales a través de los cuales las leyes europeas han contribuido a que se saque provecho de la precariedad de la mano de obra migrante. El primero es la legislación laboral. En toda Europa, desde mediados de los años setenta, diferentes leyes han autorizado el uso de contratos de muy corta duración, lo cual favorece la alternancia entre el trabajo declarado a las autoridades y el trabajo no declarado, y facilita el empleo de trabajadores temporales y subcontratados. El segundo canal es la tolerancia del estado frente a las inconsistencias en la aplicación de las leyes; de esta manera, encontramos inmigrantes ilegales que trabajan en fábricas o en empresas de construcción legales pagando impuestos y contribuyendo incluso a la seguridad social (Fouteau 2006). En tercer lugar, a pesar de los principios de libre movilización dentro de la Unión, la europeización se ha traducido en un mayor control a la movilidad de los trabajadores no europeos (Balibar 2001; Bigo y Bonelli 2003; Bigo y Guild 2005; Guiraudon 1998). Los estados fabrican inmigrantes ilegales al no permitir que los trabajadores se trasladen, aunque esto sea funcional económicamente, y crean así una situación en la cual poblaciones enteras viven bajo la amenaza de

7 Para un excelente análisis sociológico y antropológico de la tercerización, la subcontratación y las agencias temporales, véanse Jounin (2007, 2008). 
expulsión (Deltombe y Lindgaard 2006; Fouteau 2006). Finalmente, pero no es el canal menos importante, confabulados con los empleadores, los poderes judiciales promueven indirectamente la inmigración ilegal con su aceptación casi oficial de las prácticas patronales. Los directores de las agencias de empleo, así como las empresas que utilizan estas agencias, saben muy bien que están contratando inmigrantes ilegales, pero pueden declararse víctimas en caso de cualquier investigación (Jounin 2008). Los jueces imponen, si acaso, una multa, pero a menudo no se produce ninguna consecuencia. En resumen, estas prácticas estatales de impunidad muestran que el estado, lejos de "perder el control” sobre la situación (Sassen 1996), está contribuyendo a la creación de la vulnerabilidad y la precariedad en la que viven los trabajadores clandestinos.

El discurso de la criminalización ha hecho de la inmigración ilegal un "peligro" que ha invisibilizado a una gran cantidad de trabajadores (Beaud, Confavreux y Lindgaard 2006). Son invisibles estadística y socialmente, tal como lo son sus condiciones de trabajo. Sin embargo, se los criminaliza políticamente al enfatizar el rol del crimen organizado y sus vínculos con el terrorismo. Esta criminalización no permite ver que es el estado el que ha creado la contradicción entre la demanda de mano de obra y el cierre de las fronteras ${ }^{8}$, y que esta contradicción la aprovechan unos actores a los que luego se califica de criminales. Este escenario hace posible "reconciliar lo irreconciliable" (Pereira 2007); reconciliar, por una parte, la flexibilidad, la competencia y la competitividad basadas en una mano de obra barata, disciplinada e ilegal, y por la otra, administrar una seguridad basada en el seguimiento y el disciplinamiento de la población.

La criminalización de los inmigrantes ilegales legitima la toma de medidas coercitivas y permite que la soberanía del estado se ejerza de una manera muy diferente: justifica la vigilancia de los espacios públicos y privados, así como la represión mediante detenciones, expulsiones y redadas, en lugares que simbolizan protección, asilo e inmunidad, como iglesias y escuelas. La criminalización justifica intervenciones discrecionales tales como decisiones judiciales, lanzamientos y legalizaciones arbitrarias y selectivas (Bigo y Bonelli 2007). Y, al delegar poderes a entidades privadas, como aerolíneas, compañías férreas y marítimas, firmas de seguridad privada, empleadores y terceros países, el estado permite la creación de nuevas medidas de control y exclusión (Lahav 1998). Esto aumenta la vigilancia, pero también transforma la naturaleza de lo que se persigue o no se persigue. La criminalización ha llevado a un ejercicio público-pri-

8 Para una deconstrucción de este discurso, véanse Hibou (2003b); Lamloum (2003); Péraldi (2007) e Içduygu (2007). 
vado de la dominación que refleja perfectamente el orden del mundo neoliberal y su poder de redefinir las fronteras entre lo lícito, lo tolerable y lo condenable.

\section{La lucha contra el lavado de dinero o el ejercicio del gobierno privado indirecto}

El lavado de dinero siempre es el resultado de otras infracciones, tráficos, evasiones fiscales y fraudes. Por ello, comprender por medio de qué mecanismos se ha erigido como el gran peligro que desafía a la globalización contemporánea nos va a permitir interpretar la lucha contra este lavado en términos políticos. Según el discurso oficial, en efecto, la globalización financiera y la reducción de los controles permitieron que el dinero sucio en circulación proliferara desde los años setenta. Las medidas de control del sistema financiero se proponían enfrentar este "mal” sin cuestionar el principio mismo de la libre circulación de capitales; por consiguiente, se quedaron en medidas de orden cosmético y de fachada hasta principios del siglo XXI. Solo recientemente la denuncia de lavado comenzó a producir frutos en términos organizacionales: los acontecimientos del 11 de septiembre de 2001 jugaron un papel crucial e hicieron que se vinculara el lavado de dinero con el terrorismo, el financiamiento de las redes criminales y la amenaza a la seguridad de los estados; fue entonces cuando se hicieron finalmente efectivas las medidas que se habían decretado desde los años noventa. Este paso por el terrorismo es fundamental y sugiere que la lucha contra el lavado de dinero reviste una dimensión política.

Durante años, se toleró el lavado porque lo llevaban a cabo, entre otros, los actores dominantes del sistema: estados, actores financieros y grandes empresas. Esto es bien sabido entre los especialistas en estos temas, que han demostrado que el offshore era, simultáneamente, producto y parte integrante de los sistemas estatales y que los paraísos fiscales y financieros se situaban menos en las islas - aunque se las estigmatizara- que en las principales plazas financieras. Eran espacios legales para atraer flujos de dinero y optimizar fiscalmente las inversiones (Chavagneux y Palan 2006; Godefroy y Lascoumes 2004; Naylor 2002; Palan 2003). El objetivo de los grandes bancos mercantiles ha sido siempre -y lo sigue siendo - la optimización fiscal o, dicho en términos menos elegantes, la organización concreta y más o menos legal de la evasión de impuestos y del desvío de dineros. En el Mediterráneo, como en todos los sitios, los estados jugaron 
un papel importante en la construcción de los centros offshore y de los paraísos fiscales según el muy conocido esquema vicio-virtud: Madera y las islas Azores/ Portugal y Gran Bretaña; Chipre/Grecia; Malta/región mediterránea; Gibraltar/ España; Andorra/Francia y España; Mónaco/Francia e Italia; Nador/Marruecos; Benguardanne/Túnez y Libia. Los estados cerraron entonces los ojos ante la creación de sociedades ficticias, contribuyeron a promover el desarrollo de sociedades offshore en aras del desarrollo (años setenta y ochenta), y luego en aras de la salud financiera de los países (años noventa y 2000). Los estados amnistiaron a los bancos de comportamientos dudosos, a pesar de la existencia de informes categóricos acerca de sus actuaciones; favorecieron incluso las prácticas de lavado de dinero por medio de su política de bonos del Tesoro, dado que esas inversiones eran anónimas y su producido, no declarable y libre de impuestos (Hibou 1996, 2003a; McMurray 2001; Meddeb 2009).

Pero el 11 de septiembre de 2001 transformó la lucha contra el lavado de dinero en una verdadera máquina de intervencionismo burocrático (FavarelGarrigues, Godefroy y Lascoumes 2009). A partir de esta fecha, se dio un nuevo énfasis al rastreo de los flujos de capital, lo que condujo a una asociación públicoprivada que empoderó a banqueros, aseguradores, notarios, abogados, agentes estatales, comerciantes, administradores de fiducias y casinos, para vigilar la ética de sus profesiones, lo que han hecho de manera procedimental y formal, buscando ante todo prevenir eventuales reproches de las autoridades de control. De hecho, los bancos transformaron los obstáculos de la lucha contra el lavado de dinero en oportunidades de negocios (Favarel-Garrigues, Godefroy y Lascoumes 2009; Vallée 2010). Interpretaron estas reglas como un asunto de responsabilidad social de las empresas para ofrecer a sus clientes los mejores productos según sus necesidades; entendieron el lavado de dinero en términos de manejo de riesgos penales y de reputación (Hood 2007); e integraron mecanismos antilavado dentro de sistemas más amplios de vigilancia continua de las operaciones. El objetivo de seguridad se comprendió a la luz de la auditoría, es decir, en función de la capacidad de presentar documentos auditables ante los organismos de control, pruebas formales del respeto a las obligaciones legales y reglamentarias del sector (Power 1997). Para los bancos, se trataba entonces de disminuir la incertidumbre proveniente de los riesgos operacionales (Power 2004). En este contexto, la posibilidad de rastreo de los dineros es fundamental porque permite hacer el seguimiento de los flujos, remontar la cadena de transacciones e identificar, no las infracciones propiamente dichas, sino los medios de detección de pistas sospechosas que puedan llevar hasta el delincuente, el terrorista o el mafioso (Favarel-Garrigues, Godefroy y Lascoumes 2009; Garapon 2009). 
Como consecuencia, se ha producido la mercantilización del miedo y la seguridad, un fenómeno que se ha concretado en la difusión de herramientas informáticas y en la producción de normas por parte de las sociedades comerciales - principalmente estadounidenses - implementadas por oficinas especializadas que promueven kits y programas informáticos, y venden "listas” de personas (terroristas, “personas políticamente expuestas” o implicadas en la proliferación de armas de destrucción masiva), de comportamientos y de relaciones por examinar. De esta manera, la lucha contra el lavado de dinero está viviendo un proceso de comercialización de la moral y se ha convertido en un oficio, un mercado, una técnica, una especialización cuya figura emblemática es el oficial de cumplimiento (compliance officer) (Favarel-Garrigues, Godefroy y Lascoumes 2009). Su éxito no se mide por la disminución de la circulación de dinero sucio, ni por el número de flujos ilegales detectados o de sentencias dictadas por los jueces; se mide según la existencia o no, en el seno de los establecimientos financieros, de dispositivos y procedimientos de vigilancia cuyo objetivo es protegerse de sanciones profesionales y penales, y proteger las reputaciones.

En la práctica, la lucha contra el lavado de dinero hace aparecer nítidamente, no los límites entre lo legal y lo ilegal, sino entre lo legal y lo tolerable. Los paraísos fiscales y los centros financieros extraterritoriales dejan de ser incomodados una vez que adoptan medidas antilavado. En otras palabras, lo que es legal es lo que es visible en términos de procedimientos, aplicación de reglas formales y política del blame avoidance (Favarel-Garrigues, Godefroy y Lascoumes 2009; Hood 2007). La transformación de la lucha contra el lavado de dinero en una administración de las ilegalidades (Foucault 1975; Lascoumes 1997) resulta del margen que se ofrece a los banqueros y a los hombres de negocios para seleccionar los blancos que van a escrutar. Este rol de los actores privados en la designación concreta del delito no solo crea oportunidades de negocios, sugiere también su habilidad hegemónica para decidir cuáles son los objetivos legítimos de las estrategias estatales contra el crimen. Se trata de objetivos clasistas cuyo señalamiento favorece los intereses de los grandes empresarios y les permite ejercer su dominación (Coleman, Tombs y Whyte 2005). Esta dominación es también internacional, claro está, pero es ante todo un asunto de dominación interna: en última instancia, los objetivos son los pequeños criminales y la población más vulnerable (Coleman 2004). En Europa, desde el 11 de septiembre se escrutan cuidadosamente las transferencias de fondos informales, los migrantes que usan dinero en efectivo y las fundaciones caritativas islámicas (Favarel-Garrigues, Godefroy y Lascoumes 2009), y puede decirse que, por lo general, no recaen cargos penales sobre los actores dominantes de la globalización. 
De este modo, la denuncia del lavado de activos como peligro gravísimo y la urgencia que hay de detectarlo le permiten al estado actuar en un sector insignia de la globalización neoliberal. Si bien es cierto que el intervencionismo directo ya no está a la orden del día, existe una vigilancia por medio de tecnologías y listas suministradas por los cuerpos represivos, del disciplinamiento que lleva a la rastreabilidad de las operaciones, de la interiorización del control que apela al miedo a perder la reputación o a ser nombrado y avergonzado, y de la colaboración forzosa para ayudar a policías y jueces. Se trata de formas de gobierno indirectas, ejecutadas principalmente por intermediarios privados, pero que responden a procedimientos y a preocupaciones que han sido definidos en su mayor parte por los estados.

\section{La lucha contra las imitaciones y la piratería, o la justificación del nuevo control burocrático}

Las imitaciones constituyen la tercera de las "plagas" que supuestamente ponen en peligro a las economías mediterráneas. El discurso oficial, trasmitido por los órganos administrativos europeos y nacionales y por los intelectuales orgánicos de la moralidad económica, destaca los peligros que representan las imitaciones, tanto para la seguridad de los consumidores como para la sociedad en su conjunto (Comisión Europea 1998; Ministerio de Hacienda de Francia 1995, 2003; World Customs Organization IPR Strategic Group 2001; Zecri 2007). El auge reciente e importante de las imitaciones les haría daño a las empresas europeas que perderían por este motivo cuotas de mercado y, en consecuencia, empleos, de modo que verían su imagen y su reputación deterioradas. Éticamente, la falsificación sería condenable porque se fundamentaría en el saqueo de derechos de propiedad por parte de organizaciones criminales, o incluso terroristas, que los consumidores fortalecerían con su comportamiento irresponsable.

Un análisis mínimamente serio de estos textos y los trabajos científicos sobre el tema muestran el carácter fabricado de este discurso que descansa, en primer lugar, en cuantificaciones cuyas fuentes y construcción rara vez se aclaran, y que parecen tanto más dudosas cuanto se usan una primera vez. Posteriormente, esas cantidades iniciales circulan como cifras irrefutables. Esto ocurre, por ejemplo, con los datos del comercio en Europa de un supuesto $10 \%$ de imita- 
ciones, o con los 30.000 empleos que se pierden por esta causa en Francia y los 200.000 en Europa. Sin embargo, estos datos se contradicen: en un mismo texto se puede leer que los bienes falsificados no dejan de crecer en la región, aunque las estadísticas muestran una reducción innegable de las incautaciones ${ }^{9}$. Y en cuanto al peligro que implican las imitaciones, este discurso se construye sobre algunos ejemplos, no siempre europeos, pero siempre los mismos, a saber, el caso de los aceites adulterados de los años ochenta en España, los capós de Peugeot comercializados en 1999, algunos juguetes puestos en circulación en Inglaterra a principios de los años 2000 y los casos de medicamentos antipalúdicos en África.

Mucho más importante es el hecho de que las imitaciones no pueden reducirse a saqueo y robo. La diversidad de las falsificaciones es, en efecto, infinita y comprende lógicas muy diversas. Se puede distinguir entre ellas por lo menos cinco grandes grupos (Casillo 1998): en primer lugar, los productos que parecen similares pero que voluntariamente no son idénticos a los bienes en los cuales se inspiran, tal como ocurre con el perfume "Cannel n. ${ }^{\circ}$ " o con la marca "Kalvin Klain”; en segundo lugar, los productos que utilizan los mismos dibujos, los mismos colores o las mismas etiquetas que los productos de marca, con el fin de crear un aire de familia con los productos así vendidos, como si fueran "saldos" de las grandes marcas; en tercer lugar, los productos que exhiben una seña que deja suponer un vínculo jurídico o económico entre el producto propuesto y la marca de prestigio; en cuarto lugar, la imitación pura y simple, sin mención de una marca o de un modelo exclusivo; finalmente, el producto falsificado propiamente dicho, ya que no puede calificarse como tal un producto si todos los aspectos exteriores no son los mismos que los del producto copiado, incluidos el nombre y la marca. Esta diversidad en las falsificaciones responde a distintas lógicas económicas: una es la lógica de la reducción de costos, destinada a satisfacer una demanda de productos más baratos y de menor calidad (Guyer 2004); otra es la lógica del mimetismo, el aprendizaje y la industrialización tardía, que se propone alcanzar lo que hacen los países más industrializados y cuestiona menos los derechos de propiedad que la protección de técnicas y mercados por parte de dichos países ${ }^{10}$ (Delval 2009); otra es la lógica de la segmentación de los mercados y las técnicas comerciales que permite la duplicación y la venta de productos a través de redes diferenciadas (Casillo 1998; Guyer 2004); hay también una lógica del golpe de suerte y la improvisación, cuando se dan compras de lotes cuyo contenido exacto se desconoce (Péraldi 2007). Evidentemente, las consecuencias no 
son las mismas, según la categoría de la "falsificación” a la cual pertenezcan los bienes, en términos de ilegalidad y de “crimen”, en términos morales o en términos económicos y financieros.

Lo que preocupa en este tema es ver que se oculta completamente el vínculo entre falsificaciones y deslocalizaciones. Ahora bien, existe una estrecha relación entre estos dos fenómenos. Las imitaciones no proceden solamente de Asia (China) y de Europa del Este, vienen también del Mediterráneo, tanto de su orilla meridional (Marruecos, Túnez y Turquía) como de su orilla septentrional (Italia, España y Portugal). En estos países ocurre una deslocalización a gran escala, pero sobre todo, las empresas productoras de imitaciones que allí funcionan rara vez están especializadas en producir falsificaciones. Es muy común que sean las mismas empresas las que hacen lo "verdadero” y lo “falsificado”, ya que producen bienes de calidad diferente. Algunas veces fabrican intencionalmente un volumen dado de mercancía fuera de cuota, en una lógica de restricción voluntaria del mercado y de creación más o menos consciente de mercados secundarios. Con la autorización de los directivos de los departamentos de comercio exterior de las empresas, o si no, por decisión de departamentos diferentes, producen bienes de calidad menor para segmentos de mercados particulares, para las épocas de saldos, por ejemplo. Y a menudo lo hacen sin avisar a las centrales de compra, que pueden rechazar algunos lotes, por defectuosos o por daños en el embalaje, lotes que de todos modos van a ser comercializados por talleres deslocalizados. También es posible que las centrales de compra hayan evaluado mal el mercado y rechacen el excedente de los talleres, los cuales, entonces, pueden organizar las ventas de los saldos en los mercados residuales. En otros casos, finalmente, lo “falsificado" nace de la lógica misma de la deslocalización y de las compras a menor costo, y en una carrera por lograr una mayor rentabilidad no se controlan el origen ni la calidad de los productores e intermediarios ${ }^{11}$. Ocurre entonces que, muy a menudo, las falsificaciones pretenden menos engañar deliberadamente a los clientes que elevar los beneficios al máximo.

Finalmente, está el discurso emitido sin ninguna clase de pruebas de la relación de los “falsificadores” con el crimen organizado y aun con redes terroristas. He aquí un ejemplo:

Los extremistas islámicos recogieron fondos para el atentado contra el World Trade Center de Nueva York vendiendo imitaciones de camisetas; uno de los jefes de la banda de origen vietnamita Born to Kill reconoció haber ganado más de trece millones de dólares comerciando con relojes 
falsificados; y se estima que en el Reino Unido las redes criminales mueven seiscientos millones de libras esterlinas gracias al comercio de DVD pirateados - una actividad que genera ingresos a los inmigrantes ilegales-. Esas bandas operan por otra parte en otros campos de actividades ilícitas tales como el tráfico de drogas o de personas, la pornografía, las apuestas ilegales y las extorsiones. (Romulo 2009, 21-22)

Es cierto que la mafia, y la Camorra en particular, está involucrada en las falsificaciones en Italia, e incluso en países en los que invierten y subcontratan, como Túnez (Casillo 1998; D’Alessandro 2009; Lago y Palidda 2002; Saviano 2007), pero esto se debe a circunstancias muy particulares. Con todo, las imitaciones provienen en su mayoría del campo de empresas relocalizadas y de pequeños empresarios que las producen al margen de la legalidad, pero que no pertenecen necesariamente a redes criminales, aunque pueden ser forzados a pagar por protección cuando se encuentran en territorios dominados por la mafia (Saviano 2007; Schmoll 2003; Sciarrone 2010). Las instituciones que participan en la lucha contra las falsificaciones sobrestiman ampliamente el papel del crimen organizado en los delitos económicos cuando adoptan una definición estereotipada, exagerada y sistemática de lo que consideran el crimen organizado (Briquet 2007; Briquet y Favarel-Garrigues 2008; Gribaudi 2009). De hecho, los delitos económicos se producen también en los círculos legales, ahí donde la legalidad es problemática, debido a los límites porosos, las alianzas coyunturales, las trayectorias mal definidas y las relaciones en los negocios - legales o noentre empresarios y políticos, que se caracterizan a menudo por la tolerancia, la complicidad, la hibridación y la colusión. En cuestión de falsificaciones, así como en la lucha contra otros tráficos, decir que las organizaciones criminales son las autoras de los delitos es encontrar chivos expiatorios con facilidad, negarse a comprender la verdadera naturaleza y los mecanismos reales de estas actividades y reducir el problema de las imitaciones a una mera violación de reglas.

El hecho de convertir las falsificaciones en "plaga” y declarar la lucha contra ellas ha asumido formas consistentes con los modos de gobierno neoliberal, tales como las asociaciones público-privadas a través de las cuales se dictan normas y se establecen controles y medidas de autenticación en asocio con las compañías “pirateadas”, que además ayudan a establecer centros técnicos y operativos con ese propósito. Se pone así en funcionamiento un gobierno contra las falsificaciones, que se logra distribuyendo poderes entre el estado y todos los actores económicos del sector, incluyendo productores, distribuidores y consumidores. Así como en el caso del lavado de dinero, se trata de rastrear flujos sos- 
pechosos, modelos o actividades, y de monitorear y rastrear transacciones con el fin de ubicar al delincuente. Se deja entonces la vigilancia en manos de los pares y de los consumidores ${ }^{12}$.

Lo que permanece sin cuestionar e intocado es el imperativo económico de flexibilidad y competitividad que promueve la tendencia a la relocalización en búsqueda de bajos costos de producción. Tampoco se objetan las políticas implícitas de protección normativa y de control de calidad, en una época en que las políticas proteccionistas tradicionales han quedado deslegitimadas. Estos silencios no afectan en nada a un orden económico desigual, en el cual los países desarrollados e industrializados gozan siempre de una ventaja comparativa gracias a las normas que se las arreglan para imponer a nivel internacional. Al estigmatizar a actores específicos como miembros de bandas criminales organizadas - la Camorra, por ejemplo-, se crea un mito de peligro colectivo y al mismo tiempo se evita que recaigan sospechas sobre los instigadores de la relocalización y la rentabilidad, y se permite una forma encubierta de protección de los mercados a través de intervenciones indirectas.

\section{La lucha contra el contrabando y el tráfico de bienes, o la lógica de los intercambios seguros}

Finalmente, en el caso del tráfico de bienes y el contrabando, el argumento construido no se limita a esgrimir pérdidas económicas: ante el público, se han puesto en escena argumentos de seguridad, moralidad y legalidad, como en el caso del siguiente ejemplo: "las ventas ilícitas de tabaco, alcohol y cerveza de contrabando contribuyen a una economía subterránea mundial, a tal punto que en el sector del tabaco, tomado solo, el crimen organizado se ha constituido en el 'cuarto productor mundial'” (Amon y Amon 2009, 32-33). Se dice que a partir de allí las redes criminales se implantan duraderamente en el corazón de los países y construyen cabezas de puente que les sirven luego para organizar otros comercios ilícitos, en particular el tráfico de drogas. 
Aquí también, la historia es mucho más compleja e involucra en primer lugar a las grandes compañías. Para seguir con el ejemplo de los cigarrillos, es difícil demostrar la implicación activa de las compañías productoras en la organización del contrabando en Europa. Pero no quedan dudas de que tienen un interés importante en un tráfico que aumenta su mercado y cierran sus ojos ante prácticas dudosas, como la venta de cantidades superiores al consumo estimado para un país. En un mercado dominado por un número muy reducido de actores, es extraño que las compañías productoras de tabaco, que solo les venden a clientes “conocidos y de confianza”, nunca hayan detectado organizaciones criminales (Frey 1997; Guarino 2009; Kellett-Bowman 1997). De ambos lados del Mediterráneo ya está comprobado que las empresas legales juegan un papel importante en el contrabando subestimando sus importaciones, haciendo declaraciones falsas y “olvidando" declarar mercancías en la aduana (Hibou 1996; McMurray 2001; Nordstrom 2007; Péraldi 2001). La mayor parte de estos bienes que ingresan ilegalmente lo hacen por los puertos, a través de actores identificados como legales. Al acusar al crimen organizado, se deja de lado la participación de esas empresas portuarias, se oculta el hecho de que las zonas francas son a menudo menos herméticas de lo que se cree y que el contrabando se lleva a cabo también a partir de empresas deslocalizadas, con o sin el consentimiento de los empresarios o los gerentes (Meddeb 2009; Péraldi 2007a). En este caso, el discurso oficial sobre el tráfico de bienes y el contrabando se basa en una falsa dicotomía entre actores legales e ilegales.

Los estados también están fuertemente implicados en el contrabando y el tráfico de bienes. Los enclaves juegan aquí un papel importante. Así sucede con Ceuta y Melilla, plazas españolas en tierra marroquí. La institucionalización del papel contrabandista de estas dos ciudades proviene de los estados español y marroquí, y de la Unión Europea. Fueron declarados puertos francos desde 1863 y este estatus jamás les ha sido retirado; por el contrario, se ha visto reforzado por una legislación de excepción y la exención de visado a los habitantes fronterizos provenientes de Tetuán y Nador (Berramdane 2008). Ceuta recibe diariamente a cerca de diez mil marroquíes sin visa (Péraldi 2007a). Tánger, ciudad internacional desde 1920 y puerto libre tras la independencia, debe su desarrollo al uso de zonas francas en los años setenta, y especialmente en los años ochenta y noventa. Se trata de una política que se ha intensificado hoy en día con la construcción del puerto Tánger Med, que pronto se convertirá en uno de los puertos trasbordadores y de dispersión más importantes en el Mediterráneo occidental. Asimismo, los puertos mediterráneos de Túnez, Libia y Argelia facilitan el contrabando, a menudo en colusión con los estados (Bras 2005-2006; Hibou 2006; Meddeb 2009; 
Pliez 2004, 2009). Tampoco la ribera norte está exenta de este fenómeno; tenemos por ejemplo a Andorra y Gibraltar, países a los que la Unión Europea no les exigió para su adhesión incorporarse a su territorio aduanero (Guarino 2009), o el caso de las zonas libres de impuestos o con secreto bancario y sus regímenes fiscales preferenciales en las Islas Británicas, Luxemburgo o Suiza.

Por consiguiente, en el caso del contrabando, tal como sucede con las imitaciones, se está sobrestimando el papel del crimen organizado. Enfocarse en este actor y cosificarlo oscurece el papel de los demás actores ya que existen otros mecanismos que posibilitan los tráficos: los arreglos financieros para bajar impuestos, la utilización de compañías de fachada ubicadas en países con fuerte secreto bancario y el tránsito a través de paraísos fiscales o de países reputados por tener un bajo grado de cooperación judicial (Chavagneux y Palan 2006; Palan 2003). De manera similar, el hecho de que algunos puertos estén situados en territorios controlados en parte por organizaciones criminales (Nápoles, Gioia Tauro y Estambul) no quiere decir que pueda concluirse que esas organizaciones controlan y organizan esos tráficos. En Campania, Calabria o Turquía, se está más bien en lugares intermedios cuyo estatus es difícil de determinar: las fronteras entre lo legal y lo ilegal, lo oficial y lo "mafioso", entre lo "limpio" y lo "sucio" son muy borrosas y solo quedan marcadas cuando hay actuaciones judiciales (Schmoll 2003; Sciarrone 2010). En general, los actores económicos, quienesquiera que sean, sacan provecho de estas fronteras. Tal como Eiko Siniawer (2012) nos lo recuerda para comienzos del siglo XX, la investigación acerca de las mafias muestra que estas se reestructuran de acuerdo con la internacionalización y la globalización de los negocios, pero no toman el lugar de los estados y los actores legítimos. Esta investigación sugiere que existen juegos sutiles entre los actores, que tienden a ocultarse con señalamientos del tipo "crimen organizado" o "estado mafioso" (Briquet 2007; Gribaudi 2009). En realidad, el gobierno de la mafia difiere mucho de un país a otro, de una historia a otra, de un momento a otro. Los vínculos comerciales son mucho más fluidos de lo que una descripción en términos de crimen organizado sugeriría, y también mucho más débiles y puntuales; son poco vinculantes y se renegocian constantemente (Haddaoui 2009; Manry 2001; Péraldi 2007a; Schmoll 2003).

La regulación del transporte marítimo ofrece otra ilustración de este punto de vista reducido. Debido a la interacción entre las flotas mercantes, los operadores de las terminales portuarias, los estados y las regiones, este tipo de transporte ha vivido transformaciones radicales de treinta años para acá, dado que un número restringido de puertos de transbordo concentra el flujo de mercancías que se transportan en contenedores estandarizados cada vez más 
grandes. En este contexto, el Mediterráneo juega un rol creciente e importante, que representa apenas el $1 \%$ de la superficie marítima, pero el 30\% del tráfico mercante y el $25 \%$ del tráfico petrolero (Tandonnet 2008). Algeciras, en España, Marsaxlokk, en Malta, Gioia Tauro, en Italia, Damieta, en Egipto y, muy pronto, Tánger Med, en Marruecos, son los principales puertos de transbordo. Ya no es la distancia la que cuesta; en una lógica de competitividad, concentración y aceleración de los movimientos, lo que importa son las posibilidades físicas y técnicas de masificación de los flujos (Boudouin, Colin y Quercy 2002; Lavaud-Letilleul 2005; Marcadon 2002). Y si la lógica de la competitividad exige lograr reducciones en los costos, esto se hace con medios más o menos legales, como la tolerancia ante los pabellones de conveniencia y la evasión fiscal; y también con medios totalmente técnicos, como el mejoramiento en la preparación de los contenedores, y la masificación y la concentración de los flujos (Bergeron 1999; Frémont 1996). Ahora bien, esta concentración impide físicamente el control efectivo de las mercancías. De hecho, existe una ilusión de inspección (Nordstrom 2007): los puertos poseen efectivamente máquinas sofisticadas, escáneres, herramientas de inspección y de control capaces, en principio, de inspeccionarlo todo; sin embargo, es imposible controlar sistemática y concretamente la totalidad de las mercancías dada la enormidad de los movimientos y la presión por la rapidez en los despachos, los transbordos y las entregas. De esta manera, se facilita el contrabando, pero la concentración de los flujos jamás se cuestiona, ni se cuestiona tampoco la calidad en el control de las mercancías.

La lucha contra el tráfico de bienes se focaliza en cambio en la sofisticación cada vez mayor de las normas y las técnicas de seguridad. Se implementa todo un sistema de autenticaciones, rastreabilidad protegida, marcación unitaria segura, normalización y armonización de las reglas jurídicas, enmarcado en una lógica de conocimiento lo más detallado posible de los potenciales delincuentes: "la tecnología es más que una herramienta de autenticación. Es una herramienta judicial capaz de suministrar las pruebas penales necesarias para establecer los nuevos perfiles delincuenciales” (Amon y Amon 2009, 35). Y así como en el caso de los “peligros" analizados anteriormente, la intervención se delega en actores privados: sociedades de comercialización de sistemas de protección y control automatizados, sociedades administradoras de puertos, compañías de seguridad, armadores y banqueros. Esta seguridad cosificada y mercantilizada se ejerce arbitrariamente, alternando tolerancia y prohibición. Los tráficos son ampliamente conocidos; se toleran e incluso se aceptan, hasta el momento en que tiene lugar una intervención puntual, que se lleva a cabo con el fin de ejemplarizar, de mostrar que el estado sabe y es el amo, y para poner en su lugar — que debe 
seguir siendo marginal- a un actor demasiado ambicioso. Nada se pone en peligro; esto es lo que sugiere la persecución del tráfico de droga y cigarrillos de contrabando desde hace décadas. La denuncia de algunos delincuentes permite entonces estigmatizar a los culpables sin poner en tela de juicio la arquitectura misma de la globalización, sus dispositivos y prácticas.

\section{La criminalidad económica como aquelarre neoliberal}

Lo fundamental no es entonces la oposición legalidad/ilegalidad, permitido/no permitido o ético/no ético, aun cuando la lógica de la moralización se invoque a menudo: se toleran muchos comportamientos transgresores de los principios éticos más ampliamente aceptados y no se persiguen muchas actividades violatorias de la ley. La lucha contra la criminalidad se revela, ante todo, como un tema de imaginarios. Se trata del imaginario del miedo acompañado de la búsqueda de chivos expiatorios catalizadores de este miedo, un tema que compete al estado en su voluntad de acción, en un contexto que por lo demás lo limita bastante. La imagen de los aquelarres en la Italia del siglo XVI nos permite continuar con este análisis: tal como sucedía con la descripción de las sectas de brujas, que se basaba más en un imaginario de representaciones sociales y morales que en hechos reales, así sucede ahora con las organizaciones criminales, los grupos terroristas y las mafias (Ginzburg 1989). La denuncia en los casos de aquelarres utilizaba mecanismos ideológicos que daban una gran importancia a los complots y a la existencia de poderes ocultos que querían y podían hacer el mal, de modo que se transformaba el presente en una amenaza permanente. La individualización del problema, junto con la condena y el exorcismo consiguiente, permitía pasar de un modelo complejo multicausal a una relación de causalidad única y relativamente simple (Levi 1985). La denuncia de un mal así reconstruido les permitía a los poderes políticos mostrar su capacidad de protección y respuesta a la demanda de seguridad. Nacida de las transformaciones económicas, políticas y sociales, la inseguridad se transfería de esa manera a chivos expiatorios cuya identificación resultaba de las relaciones de fuerza del momento.

Los estereotipos que se aplican al mafioso, al contrabandista o al crimen organizado en su conjunto, como los principales violadores de la legalidad económica, hacen eco de forma muy extraña a los procesos que se usaban para iden- 
tificar a las brujas. No era tanto que los denunciantes y los actos de exorcismo estuvieran determinados por el conjunto de valores e ideas dominantes sino que, ante todo, eran legitimados por ellos ex post facto (Brown 1981). En nuestros días la reificación de figuras maléficas también parece tener éxito, precisamente porque permite brindar a los actores estatales, en el orden neoliberal actual y en el contexto de una búsqueda difusa de seguridad, la posibilidad de actuar en lo cotidiano por medio de una simplificación del mundo que lo hace aparecer como más previsible (Levi 1985).

Eiko Siniawer (2012) muestra también en su artículo que el énfasis en lo que llaman crimen organizado y la retórica de la criminalización son formas clásicas de subestimar y pasar por alto las prácticas ilegales de los actores legales (Coleman, Tombs y Whyte 2005; Lascoumes 1997; Slapper y Tombs 1999; Sutherland 1983). Por consiguiente, la lucha contra el crimen organizado se presenta como un aspecto del poder y la soberanía estatales que favorece el ejercicio de modelos de gobierno compatibles con la globalización económica neoliberal. Se manifiesta como un intervencionismo que no viene dictado desde arriba, por la sola decisión soberana del estado - lo que podría entrar en conflicto con los principios de apoyo a los mercados, a la competencia y a la rentabilidad-, sino que se ha establecido por delegación, desde los niveles más altos hasta los más bajos, y constituye una asociación entre actores privados y públicos, consumidores, competidores y ejecutivos de las empresas, y puede salir del territorio nacional gracias al uso de normas éticas y consensuadas, más que imponiendo el derecho mismo (Dardot y Laval 2009; Garapon 2009). Estas intervenciones, que se dan siempre en forma de negocios amistosos (friendly bussines), son una mezcla de incitaciones y directivas, autocontrol y presión sobre los pares, control por parte de subalternos y clientes - los famosos informantes-, amenaza a las reputaciones — según la técnica de nombrar para avergonzar-, invocaciones a la ética — de acuerdo con el imaginario puritano de la globalización-, listas — que demandan mucho menos pruebas que condenas judiciales - y prevención de riesgos -lo que tiende a hacer desaparecer el acto en beneficio de una esencialización del terrorista, delincuente, mafioso, estado criminal o contrabandista-.

Al ocultar las colusiones que se presentan entre criminalidad, negocios y política auspiciadas por la privatización del estado, el proceso de criminalización se presenta como la expresión misma de un modo de gobierno ahorrativo (Foucault 2004a), propio del neoliberalismo, que combina sueños de autorregulación, intervenciones discrecionales burocráticas y moralización. El estado neoliberal, con su relanzamiento por medio de políticas público-privadas, no está capitulando ni entregando su poder, sino que se está reformulando por medio de 
la definición de nuevos campos y sobre todo de nuevas modalidades de intervención. Tal como lo han mostrado los ejemplos de la lucha contra las migraciones ilegales, el lavado de activos, el contrabando y los tráficos, este relanzamiento no resulta solo del voluntarismo de un estado omnipotente y omnisciente. Es, en realidad, el fruto de una interacción permanente, el producto de tensiones, conflictos, negociaciones y compromisos entre actores variados, públicos y privados, económicos y políticos. El papel que juegan el estado y los agentes estatales en este relanzamiento es fundamental: critican las prácticas anteriores, tratan de hacer sentir la soberanía estatal y desarrollan nuevas intervenciones. Estas, sin embargo, toman la forma de las fuerzas económicas y de los actores privados con los que interactúan, y por eso las intervenciones estatales tienen que moldearse dentro del patrón de la economía política neoliberal.

He mostrado que la lucha contra los delitos económicos se da cada vez menos a través de las administraciones públicas, tales como la policía y la justicia, y cada vez más a través de la aplicación de reglas, estándares y procedimientos establecidos simultáneamente por actores estatales y privados. Este arte neoliberal de gobernar encarna en un marco político que abre la vía a una gubernamentabilidad activa que toda la sociedad requiere para someterse a los principios de libre empresa, competencia y mercado (Foucault 2004b). Esta redefinición transforma y constituye a la vez la expresión de la manera como se ejerce la dominación política: por medio de intermediarios, mayoritariamente económicos, y de mecanismos menos directos, menos institucionales y menos orientados hacia lo meramente policivo.

Traducción del inglés

María Elvira Laverde Especialista en traducción mvira@hotmail.com

\section{Referencias}

Abel, Olivier. 2009. "L’océan, le puritain, le pirate”. Esprit 356 (julio): 104-110.

Adelkhah, Fariba y Jean François Bayart. 2007. Voyages du développement. Emigration, commerce, exil. París: Karthala.

Allen, Christian. 2006. "Unruly Spaces. Globalization and Transnational Criminal Economies”. En Globalization's
Contradictions. Geographies of Discipline, Destruction and Transformation, editado por Dennis Conway y Nik Heynen, 95-105. Londres: Routledge.

Amon, Maurice y Philippe Amon. 2009. "L'innovation contre les trafics illicites: un enjeu stratégiques”, Politique Internationale 124 (verano): 32-33.

Baganha, Ioannis M. 2001. "A cada Sul o seu Norte. Dinâmicas migratórias em Portugal”. En Globalização, fatalidade ou 
utopia, editado por Boaventura de Sousa Santos, 135-159. Porto: Afrontamento.

Baker, Raymond W. 2005. Capitalism's Achilles Heel. Dirty Money and How to Renew the Free-Market System. Hoboken: Wiley.

Balibar, Étienne. 2001. Nous, citoyens d'Europe? Les frontières, l'Etat, le peuple. París: La Découverte.

Bayart, Jean François. 2006. Le gouvernement du monde. París: Fayard.

-. 2008. Global Subjects: A Political Critique of Globalization. Londres: Polity.

Bayart, Jean François, Stephen Ellis y Beatrice Hibou. 1998. The Criminalization of the State in Africa. Londres: James Currey.

\section{Beaud, Stéphanet, Joseph Confavreux y} Jade Lindgaard, eds. 2006. La France invisible. París: La Découverte.

Bergeron, Robert. 1999. "Croissance des flux de conteneurs et avènement d'un mégaport: Gioia Tauro en Calabre”. L'Information Géographique 3: 99-111.

Berramdane, Abdelkhaleq. 2008. "Le statut des enclaves espagnoles de Ceuta et Melilla dans l'Union européenne". Revue du Droit de l'Union Européenne 2: 237-260.

Bigo, Didier y Elspeth Guild, eds. 2005. Controlling Frontiers. Free Movement into and within Europe. Aldeshot; Burlington: Ashgate.

Bigo, Didier y Laurent Bonelli, eds. 2003. "La mise à l'écart des étrangers: la logique et les effets du visa Schengen”, número especial. Cultures et Conflits 49 (primavera).

—, eds. 2007. "Circulations et archipels d'exception”, número especial. Cultures et Conflits 68 (invierno).

Boltanski, Luc y Eve Chiapello. 1999. Le nouvel esprit du capitalisme. París: Gallimard.
Boudouin, Daniel, Jacques Colin y Michel Quercy. 2002. "Développement régional et organisation des échanges dans l'espace euro-méditerranéen”. Méditerranée 98 (1-2): 97-103.

Bras, Jean Philippe. 2005-2006. "Le Maghreb dans la 'guerre contre le terrorisme'. Enjeux juridiques et politiques des 'législations antiterroristes”. Année du Maghreb II: 447-467.

Briquet, Jean Louis. 2007. Mafia, justice et politique en Italie. L'affaire Andreotti dans la crise de la République, 1992-2004. París: Karthala.

Briquet, Jean Louis y Gilles Favarel-Garrigues, eds. 2008. Milieux criminels et pouvoir politique. Les ressorts illicites de l'Etat. París: Karthala.

Brown, Peter. 1981. The Cult of the Saints. Its Rise and Function in Latin Christianity. Chicago: University of Chicago Press.

Casillo, Salvatore. 1998. "L'irresistibile ascesa dell'industria del falso in Italia". Il Mulino XLVII (37): 696-710.

Castells, Manuel. 1998. The Information Age. Economy, Society and Culture. Vol. 3: The End of Millennium. Londres; Nueva York: Blackwell.

\section{Chavagneux, Christian y Ronen Palan.} 2006. Les paradis fiscaux. París: La Découverte.

Coleman, Roy. 2004. Reclaiming the Streets. Surveillance, Social Control and the City. Collompton: Willan.

Coleman, Roy, Steve Tombs y Dave Whyte. 2005. "Capital, Crime Control and Statecraft in the Entrepreneurial City". Urban Studies 42 (13): 2511-2530.

Comisión Europea. 1998. Libro verde sobre el tema de la falsificación. Bruselas: Comisión de las Comunidades Europeas.

Conway, Dennis. 2006. "Globalization of Labor. Increasing Complexity, more 
Unruly”. En Globalization's Contradictions. Geographies of Discipline, Destruction and Transformation, editado por Dennis Conway y Nik Heynen, 79-94. Londres: Routledge.

Conway, Dennis y Nik Heynen, eds. 2006. Globalization's Contradictions. Geographies of Discipline, Destruction and Transformation. Londres: Routledge.

Coutrot, Thomas. 1998. L'entreprise néolibérale, nouvelle utopie. París: La Découverte.

D’Alessandro, Libera. 2009. "Città e criminalità: il comercio come chiave interpretativa”. En Traffici criminali. Camorra, mafie e reti internazionali dell'illegalità, editado por Gabrielle Gribaudi, 334-469. Torino: Bollati Borighieri.

Dardot, Pierre y Christian Laval. 2009. La nouvelle raison du monde. Essai sur la société néolibérale. París: La Découverte.

\section{Deltombe, Thomas y Jade Lindgaard.} 2006. “Expulsés. Quand il n’est pas possible de refaire sa vie 'au pays' après avoir été expulsé de France”. En La France invisible, editado por Stéphane Beaud, Joseph Confavreux y Jade Lindgaard, 155-165. París: La Découverte.

Delval, Pierre. 2009. "Faux-semblants et vrais crimes: risques majeurs pour les consommateurs". Politique Internationale 124 (verano): 45-64.

Dillman, Bradford. 2007. "Introduction. Shining Light on the Shadows: The Political Economy of Illicit Transactions in the Mediterranean”. Mediterranean Politics 12: 123-139.

Durand, Jean Pierre. 2004. La chaîne invisible. Travailler aujourd'hui: flux tendu et servitude volontaire. París: Seuil.

Favarel-Garrigues, Gilles. 2007. La police des moeurs économiques. De l'URSS à la Russie (1965-1995). París: CNRS.
Favarel-Garrigues, Gilles, Thierry Godefroy y Pierre Lascoumes. 2009. Les sentinelles de l'argent sale. Les banques aux prises avec l'antiblanchiment. París: La Découverte.

Foucault, Michel. 1975. Surveiller et punir. Naissance de la prison. París: Gallimard.

-. 2004a. Sécurité, territoire, population. París: EHESS; Gallimard; Seuil.

-. 2004b. Naissance de la biopolitique. Cours au collège de France (1978-1979). París: EHESS; Gallimard; Seuil.

Fouteau, Carine. 2006. "Expulsables. Comment vivre sans papiers en France quand on est en règle dans son pays”. En La France invisible, editado por Stéphane Beaud, Joseph Confavreux y Jade Lindgaard, 141-154. París: La Découverte.

Frémont, Antoine. 1996. "L’espace maritime et marchand: pour une problématique”. L'Espace Géographique 3: 202-213.

Frey, R. Scott. 1997. "The International Traffic in Tobacco". Third World Quarterly 18 (2): 303-319.

Garapon, Antoine. 2009. "L'imaginaire pirate de la mondialisation”. Esprit 356 (julio): 154-167.

\section{Garson, Jean Pierre y Mouhoud El Mou-} houd. 1989. "Sous-traitance et désalarisation formelle de la main d'æuvre dans le BTP”. Notes de l'IRES 19: 36-47.

Ginzburg, Carlo. 1989. Storia notturna. Una decifrazione del sabba. Turín: Giulio Einaudi.

Glenny, Misha. 2008. McMafia. Crime without Frontiers. Londres: Bodley Head.

\section{Godefroy, Thierrt y Pierre Lascou-} mes. 2004. Le capitalisme clandestin. L'illusoire régulation des places offshore. París: La Découverte.

Gribaudi, Gabrielle. 1980. Mediatori. Antropologia del potere democristiano nel Mezzogiorno. Turín: Loescher. 
-. 2008. "Il ciclo vizioso dei rifiuti campani”. Il Mulino 435: 17-35.

—, ed. 2009. Traffici criminali. Camorra, mafie e reti internazionali dell'illegalità. Torino: Bollati Borighieri.

Guarino, Nicola. 2009. "Sigarette di contrabbando: il traffico illecito di tabacchi a Napoli dal doppoguerra agli anni novanta”. En Traffici criminali. Camorra, mafie e reti internazionali dell'illegalità, editado por Gabrielle Gribaudi, 90-111. Torino: Bollati Borighieri.

Guiraudon, Virginie. 1998. "Third Country Nationals and European Law: Obstacles to Rights' Expansion”. Journal of Ethnic and Migration Studies 24 (octubre): 657-674.

Guyer, Jane I. 2004. Marginal Gains. Monetary Transactions in Atlantic Africa. Chicago: The University of Chicago Press.

Haddaoui, Amina. 2009. "Il traffico di cannabis: dalle filiere internazionali alle reti locali marsigliesi”. En Traffici criminali. Camorra, mafie e reti internazionali dell'illegalità, editado por Gabrielle Gribaudi, 556-573. Torino: Bollati Borighieri.

Hall, Bruce y Thomas J. Biersteker, eds. 2000. Emergence of Private Authority in Global Governance. Cambridge: Cambridge University Press.

Heyman, Josiah McC., ed. 1999. States and Illegal Practices. Oxford: Berg.

Hibou, Béatrice. 1996. "Les enjeux de l'ouverture au Maroc: dissidence économique et contrôle politique”. Les Études du CERI 15 (abril): 1-42.

—. 1998a. "Retrait ou redéploiement de l'Etat?”. Critique Internationale 1 (4): 151-168.

-. 1998b. "The 'Social Capital' of the Felonious State, or the Ruse of Economic Intelligence”. En The Criminalization of the State in Africa, editado por Jean François Bayart, Stephen Ellis y Beatrice Hibou, 32-48. Londres; Oxford; Bloomington: International African Institute; J. Currey; Indiana University Press.

—, ed. 1999. La privatisation des états. París: Karthala.

-. 2002. "L'historicité de la construction européenne: le secteur bancaire en Grèce et au Portugal”. Les Études du CERI 85-86 (abril).

—. 2003a. "L’intégration européenne du Portugal et de la Grèce: le rôle des marges”. En La coopération internationale face au libéralisme, editado por Sophia Mappa, 87-134. París: Karthala.

-. 2003b. "Le partenariat en réanimation bureaucratique”. Critique Internationale 18 (1): $117-128$

—, ed. 2003c. "Les faces cachées du partenariat euro-méditerranéen”. Número completo, Critique Internationale 18 (1).

-. 2006. La force de l'obéissance. Economie politique de la répression en Tunisie. París: La Découverte.

Hibou, Beatrice y Mohamed Tozy. 2000. "Une lecture d'anthropologie politique de la corruption au Maroc: fondement historique d'une prise de liberté avec le droit”. Tiers Monde (enero-marzo): 23-47.

Hillyard, Paddy, Joe Sim, Steve Tombs y Dave Whyte. 2004. "Leaving a 'Stain on the Silence'. Contemporary Criminology and the Politics of Dissent”. British Journal of Criminology 44: 369-390.

Hood, Christopher. 2007. "What Happens when Transparency Meets Blameavoidance”. Public Management Review 9: 191-210.

Içduygu, Ahmet. 2007. "The Politics of Irregular Migratory Flows in the Mediterranean Basin: Economy, Mobility and 'Illegality'”. Mediterranean Politics 12 (julio): 141-161. 
Jounin, Nicolas. 2007. "L'illégalité soustraitée? Les conséquences du recours à des employeurs intermédiaires dans le secteur du bâtiment”. Droit Social 1: 38-45.

-. 2008. Chantier interdit au public. Enquête parmi les travailleurs du bâtiment. París: La Découverte.

Kellett-Bowman, Edward T. 1997. "Le trafic de cigarettes dans l'Union européenne”. Regard Européen (julio): 43-50.

Lago, Dal A. y Salvatore Palidda. 2002. "L'immigration et la politique d'immigration en Italie”. En Les nouvelles migrations, un enjeu européen, editado por E. Bribosia y A. Rea, 183-206. Bruselas: Complexe.

Lahav, Gallya. 1998. "Immigration and the State: The Devolution and Privatization of Immigration Control in the European Union”. Journal of Ethnic and Migration Studies 24 (octubre): 675-694.

Lamloum, Olfa. 2003. “L’enjeu de l'islamisme au cæur du processus de Barcelone”. Critique Internationale 18 (1): 129-142.

Lascoume, Pierre. 1997. Elites irrégulières. Essai sur la délinquance d'affaires. París: Gallimard.

Lavaud-Letilleul, Valérie. 2005.

"L’aménagement de nouveaux terminaux à conteneurs et le renouvellement de la problématique flux-territoire dans les ports de la Rangée Nord”. Flux 59 (eneromarzo): 33-45.

Levi, Giovanni. 1985. L'eredità immateriale. Carriera di un esorcista nel Piemonte del seicento. Turín: Einaudi.

Lowenhaupt Tsing, Anna. 2005. Friction. An Ethnography of Global Connection. Princeton; Oxford: Princeton University Press.

Manry, Véronique. 2001. “'Etre en affaire’. Compétences relationnelles, éthique de la performance et ordre social au marché des Puces”. En Cabas et containers, editado por Michele Péraldi, 279-314. París: Maisonneuve; Larose.

Marcadon, Jacques. 2002. "Géographie portuaire de l'espace euro-méditerranéen”. Méditeranéen 98 (1-2): 55-66.

Math, Antoine y Alexis Spire. 2004. "Des travailleurs jetables”. Plein Droit 2 (61): 33-36.

-. 2006. "Vers une immigration permanente de travailleurs temporaires". Documento de trabajo del Institute de Recherches Economiques et Sociales. Mode 4 de L’Accord Général sur le Commerce des Services (AGCS). Consultado el 15 de junio de 2015. http://www.ires-fr. org/images/files/DocumentsTravail/DT0 406.pdf.

McMurray, David. 2001. In and out of Morocco. Smuggling and Migration in a Frontier Boomtown. Minneapolis: University of Minnesota Press.

Meddeb, Hamza. 2009. Contrebande et réseaux marchands informels en Tunisie. París: Fasopo.

Minard, Philippe. 1998. La fortune du colbertisme. État et industrie dans la France des Lumières. París: Fayard.

Ministerio de Hacienda de Francia. 1995. "Lutter contre la nouvelle délinquance économique: les contrefaçons”. Notes Bleues de Bercy 63 (mayo): 16-31.

-. 2003. "Le plan d'action 2003-2004 du Comité National Anti-contrefaçon". Número completo, Notes Bleues de Bercy 254 (junio).

Mongin, Olivier. 2009. "De la piraterie protestante aux piratages contemporains". Esprit 356 (julio): 180-192.

Naím, Moisés. 2005. Illicit. How Smugglers, Traffickers and Copycats Are Hijacking the Global Economy. Nueva York: Doubleday. 
Naylor, R. Thomas. 2002. Wages of Crime. Black Markets, Illegal Finance, and the Underworld Economy. Ithaca: Cornell University Press.

Nordstrom, Carolyn. 2007. Global Outlaws. Crime, Money, and Power in the Contemporary World. Berkeley: University of California Press.

Palan, Ronen. 2003. The Offshore World. Sovereign Markets, Virtual Places, and Nomad Millionaires. Ithaca: Cornell University Press.

Péraldi, Michele, ed. 2001. Cabas et containers. Activités marchandes informelles et réseaux migrants transfrontaliers. París: Maisonneuve; Larose.

-. 2007a. "Economies criminelles et mondes des affaires à Tanger”. Cultures et Conflits 68 (invierno): 111-125.

—. 2007b. "Aventuriers du nouveau capitalisme marchand. Essai d'anthropologie de l'éthique mercantile”. En Voyages $d u$ développement. Emigration, commerce, exil, editado por Fariba Adelkhah y Jean François Bayart, 73-113. París: Karthala.

Pereira, Victor. 2007. "L'etat portugais et les portugais en France de 1957 à 1974". Tesis de doctorado, Institut d'Études Politiques, París.

Pliez, Olivier, ed. 2004. La nouvelle libye. Sociétés, espaces et géopolitique au lendemain de l'embargo. París: Karthala.

—. 2009. "Salloum, une bourgade bédouine sur la route de la mondialisation”. Espace Géographique 38 (1): 31-42.

Poni, Carlo. 1998. "Mode et innovation. Stratégies des marchands en soie de Lyon, $18^{\mathrm{e}}$ siècle". Revue d'Histoire Moderne et Contemporaine 45 (julio-septiembre): 589-625.

Power, Michael. 1997. The Audit Society. Rituals of Verification. Oxford: Oxford University Press.
-. 2004. The Risk Management of Everything. Rethinking the Politics of Uncertainty. Londres: Demos.

Pupier, Alain. 1992. "La fausse soustraitance dans le bâtiment et les travaux publics”. Sociétés Contemporaines 10: 153-170.

Quassoli, Fabio. 1999. "Migrants in the Italian Underground Economy”. International Journal of Urban and Regional Research 23: 212-231.

Romulo, Roberto. 2009. "Mesurer le commerce illicite pour mieux le combattre". Politique Internationale 124 (verano): 21-22.

Samson, Michel. 2006. "Travailleurs de l'ombre. Les obscures filières de l'économie française”. En La France invisible, editado por Stéphane Beaud, Joseph Confavreux y Jade Lindgaard, 427-442. París: La Découverte.

Sassen, Saskia. 1996. Losing Control: Sovereignty in an Age of Globalization. Nueva York: Columbia University Press.

Saviano, Roberto. 2007. Gomorrah. Nueva York: Farrar.

Schendel, Willem van e Itty Abraham. 2005. "Introduction. The Making of Illicitness”. En Illicit Flows and Criminal Things. States, Borders and the Other Side of Globalization, editado por Willem van Schendel e Itty Abraham, 1-37. Bloomington: Indiana University Press.

Schmoll, Camille. 2003. "Cosmopolitisme au quotidien et circulations commerciales à Naples”. Cahiers de la Méditerranée 67: 345-360. Consultado el 10 de junio de 2015. http://cdlm.revues.org/index138. html.

Sciarrone, Rocco. 2010. "Mafia and Civil Society. Economico-criminal Collusion and Territorial Control in Calabria”. En Organized Crime and States, editado por 
Jean Louis Briquet y Gilles Favarel-Garrigues, 173-196. Nueva York: Palgrave MacMillan.

Siniawer, Eiko. 2012. "Befitting Bedfellows: Yakuza and the State in Modern Japan”. The Journal of Social History 45 (3): 623-641.

Slapper, Gary y Steve Tombs. 1999. Corporate Crime. Londres: Addison Wesley Longman.

Strange, Susan. 2006. The Retreat of the State. The Diffusion of Power in the World Economy. Cambridge: Cambridge University Press.

Sutherland, Edwin H. 1983. White-Collar Crime. The Uncut Version. New Haven: Yale University Press.

Tandonnet, Jean. 2008. "La Méditerranée sous haute surveillance”. Diplomatie 35 (noviembre-diciembre): 41-43.

Tilly, Charles, ed. 1975. The Formation of National States in Western Europe. Princeton: Princeton University Press.
-. 1985. "War Making and State Making as Organized Crime”. En Bringing the State Back, editado por Peter Evans, Dietrich Rueschmeyer y Theda Skocpol, 169-191. Cambridge: Cambridge University Press.

Vallée, Olivier. 2010. La police morale de l'anticorruption. Cameroun, Nigeria. París: Karthala.

Wajsman, Patrick, dir. 2009. "Contrefaçon, fraude alimentaire et contrebande: les fléaux du XXIème siècle”, número especial. Politique Internationale 124.

World Customs Organization IPR Strategic Group. 2001. Smuggling, Counterfeiting and Piracy. The Rising Tide of Contraband and Organized Crime in Europe. Bruselas: Comisión Europea.

Zecri, Jean Luc. 2007. "Les contrefaçons: un fléau financier à l'échelle mondiale". Humanisme et Entreprise 284 (octubre): 54-92. 